\title{
HARTLEY-FOURIER COSINE GENERALIZED CONVOLUTION INEQUALITIES
}

\author{
HoAng Thi VAn AnH And NgUyen XuAN ThaO
}

\begin{abstract}
In this paper, we study some inequalities related to a certain generalized convolution for the Hartley-Fourier cosine integral transforms. Specially, we will apply these inequalities to estimate the solutions of some integral equations, differential equations and partial differential equations.
\end{abstract}

Mathematics subject classification (2010): 44A35, 45E10, 42A38.

Keywords and phrases: Convolution, Hartley transform, Fourier transform, Fourier cosine transform, convolutions inequalities.

\section{REFERENCES}

[1] M. Abramowitz and I. A. Stegun, Handbook of Mathematical Functions, with Formulas, Graphs and Mathematical Tables, National Bureau of Standards Applied Mathematics Series, 55, Washington, D.C., 1964.

[2] R. A. Adams And J. J. F. Fournier, Sobolev Spaces, 2nd ed., Academic Press, New York, Amsterdam, Elsevier Science, 2003.

[3] R. N. Bracewell, The Hartley transform, Oxford University Press, Clarendon Press, New York, 1986.

[4] M. Abramowitz and I. A. Stegun, A. Erdelyi et Al., Table of Integral Transforms, Vol. I. McGraw-Hill Book Co., New York-Toronto-London, 1954.

[5] N. T. Hong, Fourier cosine convolution inequalities and applications, Integral Transforms Special Functions, 10, 21 (2010), 755-763.

[6] H. H. Kagiwada And R. Kalaba, Integral Equations via Imbedding Methods, Applied Mathematics and Computation, No. 6. Addison-Wesley Publishing Co., Reading-Mass.-London-Amsterdam, 1974.

[7] D. S. Mitrinović, J. E. PeČArić, And A. M. Fink, Classical and New inequalities in Analysis, Kluwer Academic Published, The Netherlands, 1993.

[8] I. N. SNEDdon, The Use of Integral Transforms, McGraw-Hill. NewYork, 1972.

[9] S. SAITOH, A fundamental inequality in the convolution of $L_{2}$ functions on the half line, Proc. Amer. Math. Soc., 91 (1984), 285-286.

[10] S. SAITOH, Inequalities in the most simple Sobolev space and convolutions of $L_{2}$ functions with weights, Proc. Amer. Math. Soc., 118 (1993), 515-520.

[11] V. K. TuAn, AND M. YAmамото, Convolution inequalities and applications, Journal of Inequalities in Pure and Applied Mathematics, 3, 4 (2003), Article 50.

[12] S. Saitoh, V. K. TUAN, AND M. YAMAMOTO, Reverse weighted $L_{p}$-norm inequalities in convolutions and stability in inverse problems, Journal of Inequalities in Pure and Applied Mathematics, 1, 1 (2000), Article 7. [Online: http://jipam.vu.edu.au/v1n1/018-99.html].

[13] N. X. ThaO, V. K. Tuan, And H. T. V. Anh, On the Toeplitz plus Hankel integral equation II, Integral Transforms and Special Functions, 1, 25 (2014), 75-84.

[14] E. C. TItchmarch, Introduction to the Theory of Fourier integrals, 3rd Ed, Chelsea publishing Co., NewYork, 1986. 
[15] J. N. TSITSIKLIS, AND B. C. LEVY, Integral equations and resolvents of Toeplitz plus Hankel kernels, Laboratory for Information and Decision Systems, Massachusetts Institute of Technology. Series/Report No.: LIDS-P 1170, 1981.

[16] Vu Kim TuAn, S. B. YAKUBOVICH, On the criterion of unitary of the bilateral integral transform, Ukranian Math. J. 5, 44 (1992), 697-700 (In Russian). English transl.: A criterion for a two-sided integral transform to be unitary, Ukr. Math J. 5, 44 (1992), 630-632. 